\title{
Travestismo poético en el siglo XIX
}

\author{
EFRÉN ORTIZ DOMÍNGUEZ*
}

Resumen:

La presencia de la mujer en la historia y en las artes es un tema que recientemente ha despertado interés no sólo de las escritoras y críticas feministas, sino también de quienes, con un sentido más amplio, revaloran la importancia del arte y la cultura del siglo XIX. En ese marco, el artículo investiga la configuración de lo femenino en la sociedad demonónica, así como su manifestación, real o simulada, en la literatura escrita en el periodo. Dos casos reales y uno sospechoso de travestismo literario, muestran la idea que los intelectuales de ese siglo tienen acerca de la literatura escrita por mujeres. Irónicamente, ellos - también - consideran que la escritora es un travesti.

Palabras clave:

Travestismo literario, poesía mexicana del siglo XIX, escritura femenina, poesía y género.

Indudablemente, los años recientes han sido útiles para reflexionar acerca de la historia de la cultura, en general, y de la literatura, en particular. A la par que algunos intelectuales proclaman la anulación de la historia y el fin de la modernidad, el interés por evaluar nuestro pasado es cada vez más perceptible: se examina o se pone en entredicho la periodización convencional, las escuelas y los géneros, se hurga en archivos y fondos reservados hasta dar con nuevos

* Profesor del Instituto de Investigaciones Lingüístico-Literarias, Universidad Veracruzana. 
autores o textos, se analoza con nueva óptica a los autores clásicos, etcétera. Quizás uno de los mayores méritos de este acendrado interés por la revisión histórica consista en el abordaje de campos y temas de investigación hasta ahora soslayados. La presencia de la mujer en la historia y en las artes, por ejemplo, constituye uno de esos ricos filones que, a pesar de la insistencia y la profundidad con que ha sido tratado, no deja de brindar nuevos frutos.

En el marco de ese interés, explícito en la extensa nómina de temas e investigadores que han tratado este aspecto de nuestra historia literaria, mi aportación pareciera ser lateral: no me propongo, en primera instancia, abordar la escritura poética de las mujeres del siglo XIX. Ya otros autores lo han intentado y lo seguirán haciendo con precisión. El tema que ahora me ocupa, un caso estricto y otros dos sospechosos de travestismo en la poesía mexicana del siglo XIX, adquiere relevancia en el contexto de los estudios de género desde una perspectiva sociocultural, ya que permite advertir el imaginario social colocado detrás de la noción "mujer" y de la relación "mujer/literatura". Me interesa leerlos, en un primer momento, como episodios que salpican nuestras páginas de historia de la literatura con breves notas de humor. Ya antes alguien (Aguilar 125 y ss.) había sugerido que la nuestra fue una escritura poética excesivamente seria, grave y solemne, lo que haría contrastar visiblemente la tradición poética mexicana respecto a la de los europeos, tan desacralizadores que comienzan por no tomarse demasiado en serio a sí mismos. Teniendo como trasfondo esa aseveración, que creo injusta, quiero demostrar en este breve artículo que el humor existe, que el gracejo invade ese terreno aparentemente instalado en la solemnidad. Pero también, y en ello radica su pertinencia, me permitirá abordar una serie de asuntos más profundos: ¿qué opinión tiene la sociedad decimonónica $-\mathrm{y}$ en particular, los poetas mexicanos - acerca de las mujeres que se dedican a la literatura?, ¿cómo conciben la creación estética femenina?, ¿qué rasgos consideran ellos que posee la escritura poética de las mujeres?, ¿de qué modo simulan una escritura "femenina"?

\section{Romanticismo: el signo de la trasgresión}

Un rasgo parece signar la vida de México durante el siglo XIX: la transmutación. Si la Colonia opone resistencia a todo tipo de cambio, con el fin de asegurar la estabilidad de las jerarquías (económi- 
cas, políticas, sociales, ideológicas, incluso étnicas), un estado permanente de revolución invade, desde finales del siglo XVIII, la vida cotidiana del México recién independizado y la de todo el Occidente: son los años en que el Romanticismo, movimiento de trasgresión, de cuestionamiento de los valores establecidos, de revisión del pasado y construcción del ensueño futuro, sienta las bases del mundo moderno. Cada una de las esferas de la vida social sufre sus efectos:

Se trata, al igual que otros movimientos históricos, de un complejo fenómeno cultural y social que afectó a todos los órdenes de la vida, desde el sistema de valores básicos hasta las manifestaciones más externas de la moda. Culturalmente se presenta como una reacción anticlásica proclamando frente a la razón y las reglas ordenadoras del mundo los derechos del sentimiento y del individuo con todas sus contradicciones. (Navas Ruiz 13)

Las artes, la política, la filosofía e, incluso, las costumbres, todo adquiere un sentido de transitoriedad, de mudanza y, casos extremos, aun de inversión. Una breve pero prolija narración costumbrista de mediados de siglo, que a continuación transcribiremos extensamente, nos puede mostrar hasta qué punto y bajo qué óptica son observadas tales transformaciones:

Iba yo por el Paseo de Bucareli con un amigo llegado de la frontera. Pasó por delante de nosotros un elegante carruaje y la persona que iba dentro nos saludó. Los dos devolvimos el saludo.

- ¿Quién es esa muchacha? - me preguntó el fronterizo.

- ¡Qué muchacha! - le contesté con una carcajada-, si es Fulano.

-No, hombre, muchacha es, si lleva la raya en medio.

- Así se usa.

- Tiene un cuellito a la mitad del pescuezo, y una corbatita de encaje.

- No es de encaje. Esa prenda se llama corbata de red y así se usa.

- Todo el pecho lleno de diamantes.

- Así se usa.

-En la mano, que sacaba por la portezuela, muchos anillos, cuando menos siete $\mathrm{u}$ ocho.

-Así se usa.

-Yo le vi pulseras de diamantes. 
-No, hombre: son mancuernas para los puños de la camisa; así se usa.

- ¿Así se usa? ¡Eh! Pues ni sigo preguntando, porque si los hombres han dado en usar lo que antes sólo las mujeres usaban ¿en qué se diferenciarán?...

-Sí, hombre - le respondí-, sí se diferencian en las faldas. Todavía no les toman eso a las mujeres; pero tal vez se las tomarán.

-No; pues en mi tierra los hombres son hombres por dentro y por fuera, y las mujeres, mujeres. Allí no pregunta uno cuando lo saluda un fifiriche: “Quién es esa muchacha?"

Yo, como mexicano, tuve ganas de rebatirlo; pero vaya usted a contestar una verdad tan palmaria. La moda ha hecho mujeres a los hombres de la cintura para arriba, y yo no pude menos de confesarlo diciendo al fronterizo con un suspiro:

— ¡Lástima que tenga usted razón! (Acevedo 149-150)

Pero la moda romántica (melena larga y alborotada, ropa ajustada, propensión a la figura estilizada, expresión melancólica o de extremada sensibilidad) no solamente hizo a los hombres "una mujer de la cintura para arriba". Bajo sus efectos, se reflexiona acerca de los géneros y algunas barreras comienzan a tambalearse: el travestismo de Georges Sand, atentando contra las buenas conciencias; el sufragismo como expresión de un poder patriarcal puesto en entredicho; la insistente presencia del adulterio femenino en la narrativa de aquel siglo, que atestigua la construcción de una nueva ética amatoria, constituyen tan sólo unas cuantas marcas de tal proceso. Se trata, sin lugar a dudas, de un periodo histórico que pone sobre el tapete de la discusión el lugar y función del individuo y, todavía más allá, el lugar de los sexos.

Pero he aquí que, en este marco, la paradoja adquiere mayor relevancia: la mujer enaltecida como musa, como ángel del hogar, como progenitora universal; al propio tiempo es vilipendiada, al atribuírsele el papel de una estatua: ciega, para no darse cuenta de lo que sucede a su alrededor; sorda, para no escuchar esas voces que reclaman un cambio en la estructura global de la sociedad; muda, porque su voz, a final de cuentas, ha de estar dedicada exclusivamente al arrullo maternal, a las palabras de ternura o de la pasión. Para el mundo de los hombres, la mujer es ese ser transhistórico, transocial, destinado a recrear las condiciones de sujeción. No gratuitamente, en el siglo XIX se acentúa la lucha por la emancipación femenina. 
Por esa razón, me parece relevante el tema aquí planteado. La mujer carece, hasta el momento, de una voz. El hombre pretende hablar por ella, expresar su mundo, sus valores, su sensibilidad. Es un acto de simulación: es una voz de mujer que expresa, no obstante, la noción que de la feminidad tiene el mundo masculino. Es importante estudiar el travestismo poético a fin de recuperar esa dimensión imaginaria que de la mujer tiene la sociedad del siglo XIX; pero también, más allá, para aquilatar el peso moral de la literatura escrita por mujeres en una sociedad misógina. Una dimensión que, con frecuencia, ellas mismas adoptan, hacen suya y expresan a través de su trabajo literario, como emanado de "la naturaleza" y no de la sociedad. Un mundo presidido por la ternura, la ingenuidad, la dulzura, la delicadeza, máscaras detrás de las que se esconde su imagen inversa: la supeditación al mundo patriarcal, el menoscabo en la formación intelectual, la pretendida debilidad, rasgos que asoman explícitamente en algunas críticas que los poetas hacen de la actividad literaria femenina.

\section{Detrás de las faldas}

Para hablar del travestismo poético, entendido aquí en sentido genérico como suplantación de la identidad sexual a través de la escritura, fue María del Carmen Ruiz Castañeda, dedicada durante largos años a la investigación hemerográfica del siglo XIX, quien nos proporcionó las primeras pistas. En la introducción a un índice de revistas femeninas, indica:

La presente relación se ubica de la tercera década del siglo XIX en adelante [...] En sus páginas llegaron a colaborar varias mujeres, generalmente bajo seudónimos, y dada la reticencia de muchas de ellas (o la censura socio-cultural) para expresarse públicamente aun de manera anónima, varios varones recurrieron al curioso expediente de adoptar seudónimos femeninos, suplantando así, el punto de vista femenino (v. gr. Carlos María de Bustamante bajo el disfraz de "La Coquetilla"). (Ruiz Castañeda 81)

Ángel Muñoz consigna por lo menos ocho ejemplos más, entre los que se encuentran autores ampliamente conocidos, tales como Mariano Barazábal (1772-1807), "Bárbara", "Barbarita", "María 
Bazán"; José María de Bassoco (1795-1877), “Venus"; José Gómez de la Cortina (1799-1860), “Doña Mónica"; Vicente Riva Palacio (18321896), "Rosa Espino"; Ireneo Paz (1836-1924), “Caralampia” o “Doña Caralampia Mondongo"; Manuel García Rojas (1853-1914), "Blanca Huanita"; Manuel Gutiérrez Nájera (1859-1895), "Crysantema"; y Joaquín M. Villalobos (1879), "Saffo". Nos detendremos ahora solamente en aquellos casos donde el travestismo intenta configurar, simular o representar el punto de vista femenino en literatura; en otras palabras, en quienes publican poemas como si fuesen escritos por mujeres.

Fernando Tola, otro investigador del periodo, pone en tela de juicio la feminidad de algunas "autoras". De entre los primeros y más curiosos ejemplos dignos de sospecha está aquél de Rosario Bosero, la primera mujer en escribir una narración en México y cuya "Oda. A mis amigas" es considerada un "desahogo delicioso", un "producto débil de mi pobre ingenio" que invita al bello sexo a cultivar "el perspicaz fogoso entendimiento" (Tola, Museo tres 169). La artificiosa construcción de este poema, plagado de ripios y de términos exagerados, se contrapone violentamente a un segundo, firmado también con el mismo nombre y titulado "Una señorita mexicana a un amigo suyo, con motivo de nuestras actuales circunstancias", que se refiere a la crisis generada en México por la Guerra de los Pasteles; además, un profundo patriotismo invade al yo poético, que invita a su dedicatario a tomar las armas contra el invasor francés. No se trata ya de ese autoproclamado "débil ingenio", ni de un "pobre discurso", sino de una composición impecable, cuyas tres últimas estrofas intentan configurar una sensibilidad femenina impregnada de piedad y ternura:

Sí, la inanimada tumba

Que en la margen arenosa

Os labre mano piadosa,

Pronto me verá llegar:

Y sobre su helada masa,

Derramando eterno llanto,

Permaneceré hasta tanto

Finaliza mi penar.

La disímil factura de ambas composiciones, en verdad, da pie a interrogantes y conjeturas. No estaría tan seguro, como Tola, de que ambas composiciones pertenezcan al mismo redactor. En últi- 
ma instancia, la "Oda" parece más bien una mal conseguida simulación de un discurso femenino, y lo que denota su hipostasía es, principalmente, la innecesaria reiteración en la condición femenina de autor y dedicatarias, así como su autodescalificación como acto de escritura:
¿A quién sino a vosotras,
que sois cual yo del femenino sexo,
dedicaré un ensayo
producto débil de mi pobre ingenio?

Tola se pregunta: “Es un seudónimo, un fantasma, una invención o tal vez sólo una estrella fugaz que cruzó muy rápidamente las páginas de la historia literaria mexicana?" (Tola, Museo tres 169). Por accidente, me he topado con un poema que Severo María Sariñana dedica a dicha autora, donde celebra la delicadez de su expresión poética, hecho que no resuelve, sin embargo, la contraposición de estilos.

Pero el caso más famoso, por las curiosas derivaciones que produce en el mundo literario mexicano, tiene que ver con "Rosa Espino". Alicia Perales, al reseñar la historia de las asociaciones literarias mexicanas del siglo XIX, lo refiere como "curioso e insólito en las letras mexicanas" (Perales 89 y ss.). El Liceo Hidalgo, reconocido como una de las asociaciones literarias más relevantes del siglo XIX, sesionaba regularmente los lunes, a las ocho de la noche, en el edificio de la Universidad, entonces en estado de clausura. Las sesiones extraordinarias, o veladas, se consagraban a homenajear a alguna personalidad relevante y tenían lugar cada tres meses. Los debates concitados entre sus más de doscientos socios tenían el propósito de sentar las bases de una literatura nacionalista; en términos concretos, valoraban los aportes nacionales en los diversos autores y géneros. Pues bien, a estas reuniones asistían algunas poetas, entre las que cabe mencionar a Laureana Wright de Kleinhans, Elena Castro, Concepción Piña y Rosa Carreto. Ellas, sin embargo, desempeñaban un papel secundario: nunca fueron propuestas para los puestos directivos y raramente ocuparon un lugar central en las discusiones.

En una reunión ordinaria del año 1872, bajo el presidium de Ignacio Ramírez, fueron sometidos a examen los poemas que una desconocida poeta había publicado en las páginas de El Imparcial, dirigido por Francisco Sosa. Los comentarios de los asistentes 
hacen patente la misoginia literaria reinante: "El hecho de que apareciera en las columnas del diario una poetisa más, no tenía importancia. Había tantas..." Véanse aquí los hechos que fungen como antecedente: la abundancia de mujeres que publican en los diarios y su inclinación hacia el género poético, por un lado; por el otro, el juicio de escasa calidad concedida por los lectores, preferentemente masculinos, respecto del trabajo poético de las mujeres.

La atención que sobre Rosa Espino ponían aquellos ilustres académicos indicaba, por contraste, la excelencia concedida a su trabajo en el cual, decían, destaca el "tono delicado de sus versos que encubre una pasión llena de lirismo". De manera unánime, los socios del Liceo propusieron extender un diploma que acreditara a la novel y desconocida poeta como socia honoraria de la citada asociación. Don Anselmo de la Portilla concluyó con un juicio en el que vale la pena detenernos. A manera de elogio firme, remató la sesión asegurando: "Para escribir como Rosa Espino escribe, se necesita tener alma de mujer y de mujer y virgen. Esa ternura y ese sentimiento no lo expresa así jamás un hombre" (Perales 101-102). Como colofón, se solicitó a Sosa ser portador del homenaje y la invitación a tan recatada poeta. La fama de Rosa Espino se extendió por toda la República. Los más conspicuos, aguerridos y varoniles poetas le dedicaron composiciones. Su único libro, titulado - no ociosamente-Flores del alma, recibió elogiosos comentarios. Los adjetivos permiten configurar la idea que de una escritora tenían los poetas hombres del XIX: una mujer debía expresar un acendrado lirismo, a condición de no rebasar los límites de la pasión. Un lirismo que bordeara la ternura, que rondara entre la ingenuidad y la contención lírica.

El examen de los poemas así firmados permite nuevamente, como en el caso de la Bosero, efectuar un contraste entre aquellos poemas de corte patriótico, de lógica impecable, de argumentos contundentes, regidos por un "logos" evidentemente patriarcal, y el "pathos" (entendido aquí el término en su acepción etimológica de "afección") de la temática sentimental. Entre los primeros, podemos citar el "Canto a Hidalgo":

...Apoyada la barba sobre el pecho

$Y$ en piélago insondable de confusos

$\mathrm{Y}$ grandes pensamientos, abismado, cavando, sin sentirlo,

Con el bastón la removida tierra, 
Se agrupaban en su alma generosa

Las imágenes fieles de la guerra.

Parecíale oír entre las sombras

El eco de los bélicos clarines,

$\mathrm{Y}$ alzarse ante su vista

Por mágicos conjuros evocada,

La sangrienta batalla encarnizada;

Y escuchaba el cargar de los pesados

$Y$ fieros escuadrones,

Y los fuegos cerrados,

Y los gritos de indómitos soldados,

Y fuertes batallones

Cruzando la extensión de la llanura

Entre la nube oscura

De humo y polvo que se alza del combate;

Mesuradas también, las composiciones de corte descriptivo nos presentan una visión esencialmente objetiva del paisaje "El Alba (en la sierra)", "El medio día (en la costa)", "La tarde (en el Valle de México)", donde las que lo femenino pareciera encarnar en el uso de diminutivos, el énfasis en la suave coloración, la alusión constante a perfumes y flores. La ternura, ese rasgo que la cultura liga con un espíritu femenino, está delineado en "Un recuerdo", poema de suave nostalgia que parece justificar los adjetivos atribuidos a la "autora":

- Por qué lloras, mi madre? la decía con dulce ingenuidad,

Y ella me contestó dándome un beso:

- Es preciso llorar.

Que con lúgubre toque las campanas

Anunciándome están

Que un hombre, como todos, de esta vida

Pasó a la eternidad.

- ¿Y tú te has de morir? La dije entonces, ¿Tu amor me faltará?

Y ella sin contestar no más lloraba

y yo lloraba más. (Riva Palacio 74 )

El remate de la anécdota es, todavía, más curioso. Sólo hasta 1885, en el prólogo a las Páginas en verso del aguerrido general Riva 
Palacio, Francisco Sosa revela el engaño: "causando no sólo sorpresa sino hasta indignación en muchos círculos que, finalmente, terminaron aceptando la broma del general y reconociendo su ingenio para hacer comulgar con ruedas de molino a tanta gente" (Tola, Museo dos 48).

El último caso de posible travestismo que invocaremos nos lo proporciona también Tola. A escasos meses de concluir el siglo, Enrique Fernández Granados, "Fernangrana”, publica en El Mundo, el 11 de junio de 1899, el poema "A Lidia":

No, tu amor, no es Amor; te han engañado.

Tiene el tuyo, es verdad, forma divina:

Es casi el Dios su boca purpurina

Guarda la miel del Hibla; el delicado

Color y aroma y la tersura tiene

De las rosas de Pafos, y sostiene

El arco vencedor; de su albo cuello

Pende el carcax, que encubre

Ondulante y sutil, su áureo cabello.

Mas no, Lidia, no aguardes que me prenda;

No, tu amor no es Amor, no tiene venda.

Que no es sino una manera oblicua de hablar acerca de un amor que linda con el interés. A escasos catorce días, la misma publicación inserta la réplica que Tola considera paralela con la historia de Rosa Espino. La respuesta, a cargo de "Lidia", indica:

\section{A Fernangrana}

¿Que mi amor no es amor? ¡Cómo te engañas!

Te engañas... no: ¡cómo engañar pretendes!

Cruel en mi amor te ensañas;

Pero en mi amor, a tu pesar, te enciendes!

¿Y así me dices que el amor que en prenda

De amor te da mi corazón sincero

No es el amor, por que [sic] le falta venda?...

¡No sabes que mi amor quiere primero

Ver si tienes Amor y es verdadero!...

Respuesta ingeniosa o broma literaria que no solamente engendra esa "nostalgia literaria" de la que habla Tola, sino el interés por 
descubrir, detrás del seudónimo, la personalidad del hábil versificador y todavía más astuto argumentador que considera al amor masculino como acto de engaño.

Podemos advertir que los poemas escritos por hombres (como si lo fuesen por mujeres), quieren hacer evidente un tono dulce, tierno y delicado. Cuando los poetas se dirigen a una escritora real, de carne y hueso, la describen en términos similares. En el reconocimiento que los intelectuales mexicanos hacen a Concepción Gimeno de Flaquer, escritora y editora hispana el año de 1884, los adjetivos interpuestos son justamente ésos. Juan de Dios Peza ensalza hermosura, talento y corazón:

unes la juventud a la hermosura,

la gracia al sentimiento,

la palabra brillante a la ternura,

la bondad al talento.

Hilarión Frías y Soto confirma lo anterior, pero añade la delicadeza:

Vuestra alma es un altar lleno de flores,

de ternura purísimo santuario,

blanco lirio que encierra en su nectario

un cielo de virtud y de pasión.

Gutiérrez Nájera, por su parte, pone énfasis en el recato:

Por qué no figura en esa galería el retrato de la señora Flaquer? La discreta escritora se oculta y se recata tras de su obra: ese es el retrato de alma entera. No pudiendo ocultar su inteligencia, esconde lo que exhiben las otras: su hermosura. No intentaré, por tanto, describirla. Los retratos a pluma, se me figuran, insultos a la luz. [...] ¡Qué ideal encanto el de su cabeza pensativa! Su cutis tiene el color de la pasión, el color de Desdémona. A sus ojos, dos trémulas estrellas del crepúsculo, asoma el alma; y no adivino cómo ingratas las palabras pueden abandonar sin resistencia la cárcel perfumada de sus labios. Sé que la enoja oírse llamar bella, y por eso no intento retratarla. No; decididamente no lo hago. (Tola, Museo uno 184) 
Hasta aquí, el travestismo parecía un incidente de escasa trascendencia. Sin embargo, hemos advertido que detrás suyo se encuentra el prototipo de mujer acorde con las expectativas de una cultura, una sociedad y un siglo; además, nos proporciona una visión nítida del tipo de escritura que, según los hombres, escriben las mujeres.

\section{Imagen y contraste}

Los cuadros de costumbres nos ofrecen, a través de ciertos personajes estereotipados, un rico testimonio acerca del lugar social de la mujer en el siglo aquel. No por su atractivo folclórico, belleza física, ingenuidad o astucia, escaparán a la ironía propia del género. Vamos a revisar el lugar que ellas ocupan en tres de las publicaciones más conocidas de este tipo, para contrastarlas con la imagen de ternura y delicadeza que hemos advertido en la poesía.

El elenco femenino de El Gallo Pitagórico está constituido por cotorronas audaces a la caza de jóvenes pretendientes; por niñas coquetas, propensas a la afectación por leer las novelas románticas en boga, o al engreimiento, "mal" de las mujeres bellas; finalmente, por mujeres casadas, con una propensión "natural" hacia el adulterio. Unas cuantas líneas trazan con agilidad la consideración que merecen a Juan Bautista Morales las mujeres intelectuales:

¿Has escuchado lo que te he dicho?, pues todo es tortas y pan pintado respecto de una fea leída y escribida. No hay paciencia para sufrirla, habla más que ocho locos; como las mujeres tienen una propensión innata a manifestar sus gracias, y las feas no tienen otra que el talento, venga o no venga el caso, te hablan del congreso, del gobierno, de economía política, de jurisprudencia, etcétera, las más veces diciendo disparates garrafales pero en tono magistral y decisivo. (Morales 52)

Hilarión Frías y Soto brinda una crítica mucho más sutil en esas dos carnavalescas galerías que son Los mexicanos pintados por sí mismos y el Álbum fotográfico. En el primer texto, las estampas dedicadas a la chiera, la costurera, la china, la recamarera o la coqueta, sugieren entre líneas cierta inclinación a la liviandad (hoy decimos "liberalidad") de costumbres, por lo que insertan al género femenino en 
un marco de frivolidad. No hay, por tanto, cuadro alguno que aluda a la mujer instruida. El segundo, por su parte, conserva una única estampa que ensalza sus virtudes: se trata de la lavandera.

Es, sin embargo, en el periodismo cultural donde hemos encontrado la mayor reticencia contra la participación de la mujer en el mundo intelectual. El Ómnibus, una de las publicaciones omniscias de mayor circulación en México, a mitad del siglo, en cuyas páginas colaboran los escritores románticos más destacados (Manuel Carpio, Guillermo Prieto, Juan Valle, Luis G. Ortiz, Emilio Rey, entre otros), alberga una extensa polémica intelectual-sexista, que pone de relieve la "incomodidad moral" que supone, para los hombres, la incursión de la mujer en el mundo literario. El primer encuentro es provocado por Teodoro Guerrero, cuyo “Diccionario filosófico del amor y las mujeres", publicado entre el 14 y el 21 de septiembre de 1852, se caracteriza por un acerbo tono de ironía ante el amor y, por consecuencia, ante las mujeres. La opinión que del amor, entre otras más, tiene este casi desconocido redactor, será el detonante de la controversia. En efecto, la edición del martes 14 de septiembre, asentaba:

Amor:

Prisma que refleja muchos colores todos bellos. Teoría deleitable, que muere las más de las veces con la práctica. Vocablo indefinible. Ser fantástico concebido con pureza suma, pero que fue abortado; el siglo le ha vendido: se le ve resplandeciente con las riquezas: su voz tiene un eco arjentino. (Ómnibus 2)

Pocos años separan a este texto de El Gallo Pitagórico; ambos concuerdan en definir a la mujer como alguien guiado por el más simple interés material. La réplica ha de aguardar hasta el dos de noviembre; es anónima y tiene el cómico título de "Cuatro palabritas sueltas, o Imitación del Diccionario Filosófico del Amor y las Mujeres, por una que ni es literata ni quiere serlo". En su primer número, la redactora parte de la siguiente definición:

Amor o amores:

Los hay de muchas clases; el plural puede aplicarse al corazón de la mujer. Los hombres, como seres más privilegiados y de más alto saber, han tenido la ciencia de reasumirlos todos en uno, haciendo un amor muy grande, que le han puesto por nombre amor propio. 
Nótese la clara ironía con que alude al estatuto de hombres y mujeres: en ellas, la veleidad parece un rasgo socialmente permisible, innato (si me es permitido hablar con términos biologicistas, en boga en aquella época); no así en el de ellos, cuya "inteligencia" prohija el egoísmo y la autocomplacencia. Pero, a mi parecer, lo que evidencia de manera muy transparente la factura femenina de esta respuesta está expresado en la última colaboración de la serie, a propósito de lo que es "natural" entre hombres y mujeres:

\section{Natural:}

Los hombres se han empeñado en que las mujeres no tengan nada natural. Si estuviese en su mano, creo que nos habían de quitar hasta la forma humana.

Me parece que estas "cuatro palabritas" en especial denotan, por su contundencia y por su lógica irrebatible, que la redactora es literata - en el sentido lato del término- aunque no quiera serlo, y que el talento no está siendo utilizado, precisamente, en "disparates garrafales", como aseguraba Morales. El conocimiento comenzaba a abrir brechas entre ambos géneros.

Unos meses más tarde, la misma publicación inserta, en serie, un "Manual del Buen Tono", suscrito por las siglas "S. C.", que es bastante explícito respecto de la exclusión del sexo femenino del mundo literario. Por estar vinculada directamente con el tema de este artículo, voy a transcribir la mitad de la sección titulada "Literatura", del apartado "De los que afectan un ingenio picante":

\section{La literatura:}

Esta parte es la peor que una mujer puede representar en la sociedad.

Estos personajes son herederos en línea recta de las mujeres instruidas de Molière, y la sociedad los estima en poco.

Son una especie de hermafroditas que han conservado de la mujer los defectos, y no han adoptado del hombre sino la hinchazón de la vanidad literaria, las ridiculeces y algunas veces las malas costumbres.

La mujer que tiene un verdadero talento sale de este rango para entrar en el de literato, de autor, de escritor. Estas mujeres son raras, y no hablo de ellas.

En ellas se opera una metamorfosis; el talento las ha vuelto un hombre, y por eso se las llama un literato. 
Entonces, desde el punto de vista de las "buenas costumbres", la mujer intelectual ... ¡también es un travesti! ¿Cuál es, por lo tanto, su lugar "natural", de acuerdo con los valores de esta sociedad? Los puntos finales de la columna exponen, de manera muy clara, la conducta que el redactor suponía como el "ideal femenino":

La mujer que posee un talento verdadero, debe regocijarse de ello con el único pensamiento de que le servirá para la educación de sus hijos.

$[\ldots]$

16. ¡Feliz! ¡mil veces feliz! La mujer bastante inteligente para no buscar la felicidad sino en el seno de su familia.

Con una receta tan sencilla ¿habría espacio, en aquellos años, para la desventura femenina?

\section{Conclusiones}

El recorrido que he efectuado a través de la poesía (escrita por hombres pero, presumiblemente, delineada según una sensibilidad femenina), los cuadros de costumbres y el periodismo ayuda a entender el problemático lugar de la mujer no sólo en el marco de la literatura, sino en otro, más amplio: aquél de su inserción como género, en el contexto de esa sociedad que vive los estremecimientos de una transformación integral. Cuando el escritor, firmando y escribiendo "como mujer", adopta el papel de travesti intelectual, no está jugando una simple broma literaria, sino que interpone un punto de vista específico: quiere modelar una conducta, una sensibilidad, un tipo de escritura. Espera que las mujeres piensen, actúen y escriban de acuerdo con tal modelo.

Visto el cuadro desde esta perspectiva ahora parece mucho más meritorio el atrevimiento de las poetas, narradoras y dramaturgas del siglo XIX: en el entorno de una sociedad y un mundo intelectual eminentemente masculinos, han tenido el atrevimiento de proponer "otras formas de crear conocimiento y de entender la existencia en el mundo con el fin de humanizar el privilegio de la vida". (López González 48) 


\section{Bibliografía}

Acevedo Escobedo, Antonio. Almanaque Literario. Espejo del siglo XIX para 1960. México: INBA, 1959.

Aguilar, Luis Miguel. La democracia de los muertos: Ensayos sobre poesía mexicana, 1800-1921. México: Cal y Arena, 1988.

Aguilera, Raymundo. "Hacia una imagen de la mujer en la poesía femenina mexicana del siglo XIX. Una configuración de su escritura." Tesis de Licenciatura. Xalapa: Universidad Veracruzana, 1996.

Anderson, Bonnie y Judith Zinsser. Historia de las mujeres: una historia propia (2 vols.). Barcelona: Crítica, 1992.

Balderston, Daniel y Donna J. Guy (comps.). Sexo y sexualidades en América Latina. Buenos Aires. Paidós, 1998.

Campuzano, Luisa (comp.). Mujeres latinoamericanas: Historia y cultura. Siglos XVI al XIX (2 vols.). La Habana: Casa de las Américas/ Universidad Autónoma Metropolitana, 1997.

Carner, Françoise. "Las mujeres y el amor en el México del siglo XIX a través de sus novelas (1816-1868)." Tesis de Maestría. México: El Colegio de México, 1975.

Domenella Ana Rosa y Nora Pasternac (comp.): Las voces olvidadas. México: El Colegio de México, 1991.

El Ómnibus. Periódico literario, agrícola y fabril, de religión, variedades y avisos (1:101). México, septiembre de 1852.

Frías y Soto, Hilarión et al. Los mexicanos pintados por sí mismos. (Edición facsimilar). México: Biblioteca Nacional, 1935.

Álbum fotográfico. México: Las Letras Patrias, 1954. 
González, Soledad y Julia Tunón. Familias y mujeres en México. México: Colegio de México, 1997.

Granillo, Lilia: “El silencio de la sombra fugitiva. Poesía femenina mexicana del siglo XIX." Literal 20 (1994).

Lagarde, Marcela. Los cautiverios de las mujeres: madresposas, monjas, putas, presas y locas. México: UNAM, 1997.

López González, Aralia (coord.). Sin imágenes falsas. Sin falsos espejos. Narradoras mexicanas del siglo XX. México: El Colegio de México, 1995.

Morales, Juan Bautista. El Gallo Pitagórico. 3a. ed. México: UNAM, 1991.

Muñoz, Ángel. Fichero bio-bibliográfico de la literatura mexicana del siglo XIX (2 vols.). México: Factoría, 1995.

Navas Ruiz, Ricardo. El Romanticismo español. Historia y crítica. 2a. ed. Salamanca: Anaya, 1973.

Pacheco, José Emilio. "Reloj de arena. Ignacio Rodríguez Galván, el primer escritor mexicano." Letras Libres 1:12 (1999): 16-19.

Parcero, María de la Luz. Condiciones de la mujer en México durante el siglo XIX. México: INAH, 1992.

Perales, Alicia. Asociaciones literarias mexicanas del siglo XIX. México: Imprenta Universitaria, 1957.

Ramos, Carmen et al. Presencia y transparencia: la mujer en la historia de México. México: Colegio de México, 1992.

Riva Palacio, Vicente. Poesía completa. México: CONACUlta / UNAM /Instituto Mexiquense de Cultura, 2000. 
Robles, Martha. La sombra fugitiva (2 vols.). México: UNAM, 1985.

Ruiz Castañeda, María del Carmen."Mujer y literatura en la hemerografía: Revistas literarias femeninas del siglo XIX." Fuentes humanísticas 4.8. (1994).

Sariñana, Severo María. Trovas mexicanas. México: Imprenta de Juan R. Navarro, 1850.

Tola, Fernando. "Altamirano y la teoría de las generaciones en el siglo XIX." Sábado. 1156 (1999): 1-3.

Museo literario [uno]. México: Premiá, 1984.

Museo literario [dos]. México: Premiá, 1986.

Museo literario [tres]. México: Premiá, 1990. 